Vol. XXII No 32016

\title{
METHOD TO ESTABLISH THE OVERALL RELIABILITY OF THE MILITARY HUMAN-MACHINE SYSTEMS
}

\author{
Octavian-Ioan BOGDAN \\ "Nicolae Bălcescu" Land Forces Academy, Sibiu, Romania \\ obogdan@armyacademy.ro
}

\begin{abstract}
The man-machine system consists of two subsystems fundamentally different, one representing the human factor and the other the technical equipment. The reliabilities of the two subsystems are treated with different methods, given their different nature. Consequently, linking them to use a single indicator of reliability is achieved with difficulty. This article introduces a new indicator of the system reliability indicating the overall reliability of the man-machine system and proposes a method for calculating this indicator.
\end{abstract}

Keywords: man-machine system, reliability, human factor

\section{Introduction}

The man-machine system (humanmachine system) is an elementary sociotechnical system, composed of the human factor interacting with the technical equipment [1]. The problem of the human factors is the subject of several works including the NUREG-0700 (2002) and Mil Stand 1492F (2003) military standards [2].

In the military operations, the relation of the human factor and the technical equipment is very important. A good relation between those ensures often the success of the operation.

The reliability of an entity is its aptitude to fulfill its function in a given time and in given conditions. In order to calculate the reliability of the technical equipment we used methods from the field of reliability such as: the structural model method, the total probability method, etc. But the reliability of the human factor is difficult to determine with these methods because of the psychological aspects that must be considered. The basic concept of defining the human reliability is the human error and not the concept of the fault that is specific of the technical equipment [1]. In the late 1950s the first attempts of the human reliability quantification have their origin in the aerospace industry. Afterwards, the industries, faced high risks, for example, nuclear and chemical industries joined in this effort [3].

There are several methods for assessing the reliability of the human factor. These include: Absolute Probability Judgment (APJ), Paired Comparison (PC), Technique for Human Error Rate Prediction (THERP), Human Error Assessment and Reduction Technique (HEART), Influence Diagram Approach (IDA), Human Cognitive Reliability Method (HCR) [3].

This paper proposes a method of the calculation of the overall reliability of the military man-machine system, by which the human reliability is modeled by a weighted probability. 
2. The human-machine system reliability

One of the forms of decomposition of human-machine system is the serial configuration [1]. According to this configuration, the human-machine system has the structure shown in Figure 1.

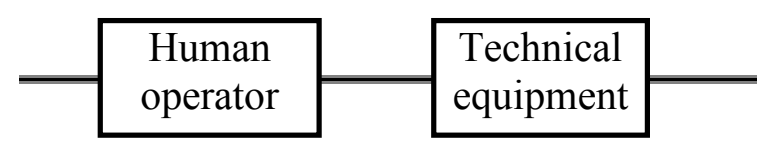

Figure 1. The serial configuration of the human-machine system

For this configuration, the reliability of the system is calculated with relation (1):

$H T R=H R \cdot T R$

where: $\boldsymbol{H T} \boldsymbol{R}$ is the human-machine system reliability, $\boldsymbol{H R}$ is the human operator reliability, $\boldsymbol{T} \boldsymbol{R}$ is the technical equipment reliability.

If for the technical equipment there are the methods of the reliability calculation and the values of the reliability indicators, for the human operator things are more complicated.

Reason [1, 4] has established three based types of the human errors. They are:

1),slips (attentional failures): intrusion, omission, reversal, misordering, mistiming;

2) lapses (memory failures):omission of planned items, place-losing, forgetting intentions;

3) mistakes (rule and knowledge-based): misapplication of good rules, application of bad rules, many types of knowledge-based mistake."[4]

For the determination of the human reliability human error probability (HEP) is used. It is [3]:

$$
H E P=\frac{\text { Number of human errors }}{\text { Total number of opportunities for error }}
$$

HEP shows the likelihood of an error occurring during of a specific task [3]. The human reliability (HR) is the likelihood of the successful performance of the task and is expressed by [3]:

$H R=1-H E P$.

\section{The proposed method for}

\section{determination of human reliability}

We consider the set of the types of the possible human errors:

$E=\left\{e_{1}, e_{2}, \cdots, e_{n}\right\}$

and the set of the field experts:

$\boldsymbol{F}=\left\{\boldsymbol{f}_{\mathbf{1}}, \boldsymbol{f}_{2}, \cdots, \boldsymbol{f}_{\boldsymbol{m}}\right\}$

who express themselves on the gravity of the each type error.

We consider the set of the numbers:

$$
\left\{N_{1}, N_{2}, \cdots, N_{n}\right\}
$$

where: $N_{1}$ is de number of human errors of type $\boldsymbol{e}_{1}, N_{2}$ is de number of human errors of type $e_{2}, \ldots, N_{n}$ is de number of human errors of type $\boldsymbol{e}_{\boldsymbol{n}}$.

In a simplistic approach, if $\boldsymbol{M}$ is the total number of the opportunities for error, the human error probability is:
$H E P=\frac{\sum_{i=1}^{n} N_{i}}{M}=\sum_{i=1}^{n} \frac{N_{i}}{M}$.

In equation (7) $\frac{\boldsymbol{N}_{\boldsymbol{i}}}{\boldsymbol{M}}$ represents the human error probability of the type of the error $\boldsymbol{e}_{i}$ reported at of the total number $\boldsymbol{M}$.

This approach is false, because the errors $\boldsymbol{e}_{1}, \boldsymbol{e}_{2}, \cdots, \boldsymbol{e}_{n}$ have the different numbers of opportunities of accomplishment. These are: $\boldsymbol{M}_{1}, \boldsymbol{M}_{2}, \ldots, \boldsymbol{M}_{\boldsymbol{n}}$. Consequently, we have the following human error probabilities:

$H E P_{1}=\frac{N_{1}}{M_{1}}$,
$H E P_{2}=\frac{N_{2}}{M_{2}}$,

$\operatorname{HEP}_{n}=\frac{N_{n}}{M_{n}}$,

We consider the matrix (the vector) of the human error probabilities:

$\boldsymbol{P}=\left(\boldsymbol{H E P} \boldsymbol{P}_{1}, \boldsymbol{H E} \boldsymbol{P}_{2}, \cdots, \boldsymbol{H E P} \boldsymbol{P}_{\boldsymbol{n}}\right)$.

The field experts give a subunitary weight of the each error type, the sum of the all 
weights being equal to one. Result the following matrices of the expert weights:

$$
W_{k}=\left(\begin{array}{c}
w_{k 1} \\
w_{k 2} \\
\vdots \\
w_{k n}
\end{array}\right) . \quad k=1, \cdots, m
$$

The weighted human error probability results from the following matric relation:

$$
\begin{aligned}
& P_{k}=\frac{1}{\sum_{i=1}^{n} H E P_{i}}\left(P \times W_{k}\right)= \\
& =\frac{1}{\sum_{i=1}^{n} H E P_{i}}\left(\sum_{i=1}^{n} w_{k i} \cdot H E P_{i}\right) .
\end{aligned}
$$

with $\boldsymbol{k}=\mathbf{1}, \cdots, \boldsymbol{m}$.

We build the matrix:

$$
A=\frac{1}{\sum_{i=1}^{n} H E P_{i}}\left(\begin{array}{c}
\sum_{i=1}^{n} w_{1 i} \cdot H E P_{i} \\
\sum_{i=1}^{n} w_{2 i} \cdot H E P_{i} \\
\sum_{i=1}^{n} w_{m i} \cdot H E P_{i}
\end{array}\right)
$$

The experts have the different competences to assess the gravity of the errors. We quantify the expert competences with some competence coefficients, having the sum equal to one. With these coefficients, we build the competences matrix:

$$
B=\left(c_{1}, c_{2}, \cdots, c_{m}\right) \text {. }
$$

The human error probability is obtained by aggregation $[\mathbf{5}, \mathbf{6}, \mathbf{7}]$. The matrix:

$(H E P)=B \times A$, where $\boldsymbol{H E P}$ is the human error probability, calculated by relation:

$H E P=\frac{\sum_{k=1}^{m} c_{k}\left(\sum_{i=1}^{n} w_{k i} \cdot H E P_{i}\right)}{\sum_{i=1}^{n} H E P_{i}}$.

Thus, according relation (3), the human reliability is:

$$
H R=1-\frac{\sum_{k=1}^{m} c_{k}\left(\sum_{i=1}^{n} w_{k i} \cdot H E P_{i}\right)}{\sum_{i=1}^{n} H E P_{i}}
$$

where: $\boldsymbol{c}_{\boldsymbol{k}}$ is the competence coefficient of expert $\boldsymbol{k}, \boldsymbol{w}_{\boldsymbol{k}}$ is the weight of the human error probability of error $\boldsymbol{e}_{\boldsymbol{i}}$ given by expert $\boldsymbol{k}$ and $\boldsymbol{H} \boldsymbol{E} \boldsymbol{P}_{\boldsymbol{i}}$ is the human error probability of error $\boldsymbol{e}_{\boldsymbol{i}}$.
For evaluating the reliability of the humanmachine system, called overall reliability of the system, we use relation (1).

\section{Case study}

We consider the human-machine system, composed of a military radio installation and the military radio operator. We suppose the following human errors, which military radio operator can make in the operation of the radio installation:

$-\boldsymbol{e}_{1}-$ the unawareness of the working procedures;

$-\boldsymbol{e}_{2}$ - the misapplication of the working procedures;

$-\boldsymbol{e}_{3}$ - the failure to comply with work procedures.

We consider the human error probabilities:

$$
\begin{aligned}
P=\left(H E P_{1}, H E P_{2}, H E P_{3}\right) & = \\
= & (0.35,0.42,0.24)
\end{aligned}
$$

We suppose that on the gravity of the errors express four experts $\boldsymbol{f}_{1}, \boldsymbol{f}_{2}, \boldsymbol{f}_{3}, \boldsymbol{f}_{4}$, that give the following weights:

$$
\begin{aligned}
& W_{1}=\left(\begin{array}{l}
0.3 \\
0.5 \\
0.2
\end{array}\right), W_{2}=\left(\begin{array}{l}
0.2 \\
0.4 \\
0.4
\end{array}\right), \\
& W_{3}=\left(\begin{array}{l}
0.4 \\
0.5 \\
0.1
\end{array}\right), W_{4}=\left(\begin{array}{l}
0.3 \\
0.3 \\
0.4
\end{array}\right) .
\end{aligned}
$$

The competences matrix is:

$$
B=\left(c_{1}, c_{2}, c_{3}, c_{4}\right)=(0.2,0.3,0.4,0.1)
$$

For evaluating the human error probability of the operator we use relation (16). We obtain:

$$
H E P=0.356 .
$$

The human reliability of radio operator is:

$$
H R=1-H E P=0.644 .
$$

If we suppose the reliability of the radio installation is: $\boldsymbol{T} \boldsymbol{R}=\mathbf{0 . 8 5}$, the overall reliability of the human-machine system is:

$$
H R T=H R \cdot T R=0.5474 .
$$

\section{Conclusions}

The presented method can be used to assess the overall reliability as forecast indicator for the military human-machine systems. This indicator can help with the preparation of the military operations. In order for the method to be applicable one must know the types of human errors that 
can occur in the exploitation of different types of military technical equipment. Moreover, the values of the reliability indicators of the components of the used military technical equipment should be taken into account.

\section{References}

[1] Polet, Ph., Modélisation des Franchissments de Barrières pour l'Analyse des Risques des Systèmes Homme-Machine, p. 37, p.61, p. 65, PhD Thesis, University of Valenciennes and of Hainaut-Cambrésis, France, 2002.

[2] Spurgin, A.J, Human Reliability Assessment. Theory and Practice, p. 33, CRC Press, 2010.

[3] Cox, S., Tait, R., Safety, Reliability and Risk Management: An Integrated Approach, second edition, pp. 76-77, Oxford: Butterworth-Heinemann, 1998.

[4] MIL-HDBK-338B: Military Handbook-Electronic Reliability Design Handbook, Section 7, pp. 161 - 167, Department of Defense-USA, 1998.

[5] Kruse, R., Schwecke, E., Heinsohn, J., Uncertainty an Vagueness in Knowledge Based Systems. Numerical Methods, p.79, Springer-Verlag Berlin Heidelberg, 1991.

[6] Bogdan, O.I., Fuzzy Method to Establish the Impact of Human Errors on Man-Machine Systems, The $20^{\text {th }}$ International Conference The Knowledge-Based Organization, Conference Proceedings 3, pp. 17-22, The „Nicolae Bălcescu” Land Forces Academy, 12-14 June, 2014.

[7] Bogdan, O.I., Method to Establish the Optimal Variant of the Tehnical Project, The $21^{\text {th }}$ International Conference The Knowledge-Based Organization, Conference Proceedings 3, pp. 9-12, The „Nicolae Bălcescu” Land Forces Academy, 11-13 June, 2015. 